but only in B-mode. Significant improvements are still needed to reliable demonstrate blood flow detection by PD mode.

REFERENCES:

[1] D'Agostino, M.A., et al., RMD Open, 2017. 3(1): p. e000428.

Table 1. Concordance between a handheld and a conventional cartbased US device in B-mode

\begin{tabular}{|c|c|c|c|}
\hline \multicolumn{4}{|c|}{ Agreement by site } \\
\hline & $\mathrm{N}$ joints (\%) & Concordance (\%) & Kappa $95 \% \mathrm{Cl}$ \\
\hline Overall & 186 & 97 & $0.90(0.89$ to 0.94$)$ \\
\hline Wrist & $32(17.2)$ & 96 & 0.86 (0.77 to 0.93$)$ \\
\hline $\begin{array}{l}\text { Finger/toe joint (MCP, PIP, DIP, } \\
\text { MTP) }\end{array}$ & $114(61.3)$ & 97 & 0.92 (0.88 to 0.95$)$ \\
\hline Elbows & $11(5.9)$ & 95 & $0.87(0.75$ to 0.97$)$ \\
\hline Shoulder & $4(2.2)$ & 100 & 1.00 (NA to NA) * \\
\hline Knee & $20(10.7)$ & 98 & $0.96(0.90$ to 1.00$)$ \\
\hline Ankle & $5(2.7)$ & 100 & 1.00 (NA to NA) * \\
\hline \multicolumn{4}{|c|}{ Agreement by pathological finding } \\
\hline Joint effusion & & 95 & 0.81 (0.68 to 0.92$)$ \\
\hline Synovitis & & 94 & 0.87 (0.79 to 0.93$)$ \\
\hline Synovitis OMERACT grade $(0-3$ & & 90 & $0.84(0.76$ to 0.91$)$ \\
\hline Bone enlargement & & 98 & $0.88(0.71$ to 1.00$)$ \\
\hline Erosion & & 98 & $0.89(0.77$ to 0.89$)$ \\
\hline Tenosynovitis & & 98 & 0.83 (0.61 to 0.96$)$ \\
\hline Entheseopathy & & 100 & 1.00 (NA to NA) * \\
\hline Bursitis & & 97 & $0.90(0.89$ to 0.94$)$ \\
\hline
\end{tabular}

* unreliable kappa statistics because of small number of shoulders/ankles examined and small number of entheseopathies

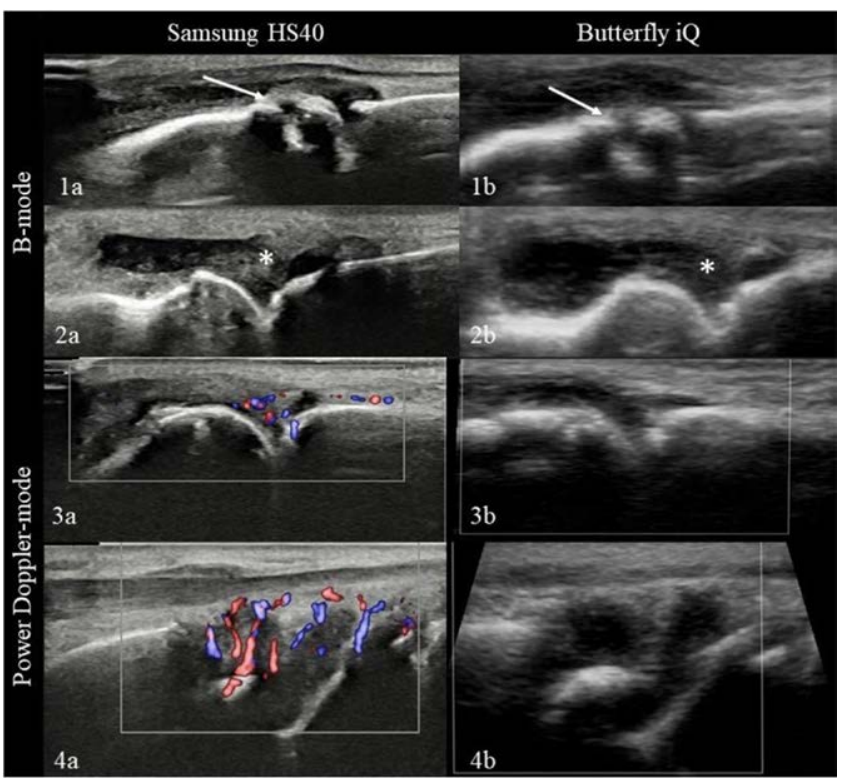

Figure 1. Pathological US findings in MCP joints $(1,2,3)$ and wrist $(4)$ depicted by the two different ultrasound devices

B-mode erosive (arrow) and synovial (asterisk) changes could be detected by both devices (1-2), while PD changes of different grades only by the conventional US device (3-4).

Acknowledgements: This study was supported by the Deutsche Forschungsgemeinschaft (DFG- FOR2886 PANDORA and the CRC1181). Additional funding was received by the Bundesministerium für Bildung und Forschung (BMBF; project METARTHROS, MASCARA), the H2020 GA 810316 - 4D-Nanoscope ERC Synergy Project, the IMI funded project RTCure, the Emerging Fields Initiative MIRACLE of the Friedrich-Alexander-Universität Erlangen-Nürnberg, the Else Kröner-Memorial Scholarship (DS, no. 2019_EKMS.27) and Innovationsfond Lehre / FAU Erlangen-Nürnberg 2019.

Disclosure of Interests: None declared

DOI: 10.1136/annrheumdis-2021-eular.2163

\section{POS1395 1 ASSESSMENT OF MICROVASCULAR INVOLVEMENT IN LUPUS NEPHRITIS PATIENTS BY RETINAL OCT- ANGIOGRAPHY AND KIDNEY BIOPSIES}

S. Ferrigno ${ }^{1}$, P. Conigliaro ${ }^{1}$, C. Giannini ${ }^{2}$, C. Nesi ${ }^{2}$, G. L. Fonti ${ }^{1}$, M. Cesareo ${ }^{2}$, R. Perricone ${ }^{1} .{ }^{1}$ University of Rome Tor Vergata, Rheumatology, Allergology and Clinical Immunology, Department of "Medicina dei Sistemi", Rome,
Italy; ${ }^{2}$ University of Rome Tor Vergata, Ophthalmology Unit, Department of Experimental Medicine and Surgery, Rome, Italy

Background: Lupus Nephritis (LN) and retinopathy are organ-threatening manifestation of Systemic Lupus Erythematosus (SLE) and both share common pathophysiology represented by microvascular damage. Optical coherence tomography angiography (OCTA) is a recent non-invasive technique showing retinal vascular damage.

Objectives: To analyze retinal microvascular alterations in SLE-LN patients and investigate correlations between ocular and renal involvement.

Methods: We recruited SLE-LN patients and healthy controls ( $\mathrm{HC}$ ) age and sex -matched. Patients underwent rheumatological evaluation, including clinical, laboratory, kidney function and kidney biopsies examination.

Patients and $\mathrm{HC}$ underwent a complete ophthalmological evaluation including eye definition color retinography and OCTA whole image, parafovea and fovea vessel density assessment of superficial and deep retinal capillary plexus. Parafovea and fovea thickness, fovea avascular zone (FAZ) area and perimeter were detected.

Statistical analysis was performed using: $\chi 2$ test, unpaired t-test, Mann Whitney $\mathrm{U}$ test, Pearson or Spearman rank correlation and ROC curve analysis.

Results: 48 eyes of 24 SLE-LN patients and 44 eyes of $21 \mathrm{HC}$ were evaluated. Table 1 shows demographic, clinical, laboratory and histological parameters.

Figure 1 shows results of OCTA data and relative AUC curves and ROC analysis. Analysis of OCTA data showed a significative reduction of vessel density in SLE-LN compared to $\mathrm{HC}$ regarding the following parameters: superficial whole en face, parafovea and fovea density (Figure 1A-C), deep whole en face and deep fovea density, (Figure 1D-E), parafovea and fovea thickness (Figure 1F-G), FAZ area and perimeter (Figure $1 \mathrm{H}-\mathrm{I}$ ).

OCTA data were correlated with demographic, clinical and histologic features of patients showing negative correlation between: SLE duration and both superficial $(p=0.03 ; r=-0.3)$ and deep $(p=0.004 ; r=-0.4)$ whole en face density; LN duration and superficial whole en face $(p=0,05 ; r=-0.4)$ and parafovea $(p=0.007 ; r=-0.4)$ density, deep whole en face $(p=0.004 ; r=-0.4)$ and fovea $(p=0.01 ; r=-0.4)$ density and parafovea thickness $(p=0.004 ; r=-0.3)$ SLEDAI-2K and both superficial and deep fovea density $(p<0.0001, r=-0.6$ and $p=0.0, r=-0.4$ respectively); BUN and superficial whole en face density $(p=0.003 ; r=-0.5)$ and parafovea $(p=0.004 ; r=-0.4)$ density and deep fovea density $(p=0.03 ; r=-0.3)$; serum creatinine and deep whole en face density $(\mathrm{p}=0.004 ; \mathrm{r}=-0.4)$.

Positive correlation was found between $L N$ duration and FAZ area $(p=0.01 ; r=$ $0.4)$; creatinine clearance and both deep whole en face $(p=0.05 ; r=0.3)$ and fovea $(p=0.0007 ; r=0.5)$ density.

OCTA data analysis showed a reduction in superficial $(p=0.02)$ and deep $(p=0.009)$ whole en face density in patients with $L N$-vascular lesions assessed by kidney biopsy. In this group, patients with intimal hyalinosis showed a reduction in deep whole en face density $(p=0.04)$ compared to those without intimal hyalinosis.

Conclusion: Preliminary results suggest a correlation between retinal microvascular alterations and kidney function and histologic lesions encouraging the use of OCTA measurement as a potential biomarker of systemic vascular involvement.

Table 1.

\begin{tabular}{llll}
\hline & SLE & HC & P value \\
& & & \\
& $\mathrm{N}=24$ & $\mathrm{~N}=21$ & \\
\hline Age (years) & $44.4 \pm 13.8$ & $38.3 \pm 10.4$ & $\mathrm{~ns}$ \\
Female (n/\%) & $21 / 87.5$ & $17 / 81$ & $\mathrm{~ns}$ \\
BCVA (logMAR) & $0.01 \pm 0.05$ & $0.0 \pm 0.1$ & $\mathrm{~ns}$ \\
Disease duration (months) & $177.6 \pm 126.6$ & $/$ & \\
LN duration (months) & $108 \pm 97$ & $/$ & \\
SLEDAl-2K & $6.8 \pm 5$ & $/$ & \\
Creatininemia (mg/dl) & $0.9 \pm 0.3$ & $/$ & \\
BUN (mg/dl) & $39,6 \pm 17.6$ & $/$ & \\
Creatinine clearance (ml/min) & $99.2 \pm 53.7$ & $/$ & \\
Proteinuria (mg/24h) & $432.8 \pm 524.5$ & $/$ & \\
GMN class III-IV (n/\%) & $19 / 77.7$ & $/$ & \\
GMN class III-V (n/\%) & $5 / 22.2$ & $/$ & \\
Kidney biopsy active lesions (n/\%) & $15 / 62.5$ & $/$ & \\
Kidney biopsy chronic lesions $(\mathrm{n} / \%)$ & $15 / 62.5$ & $/$ & \\
Kidney biopsy vascular lesions $(\mathrm{n} / \%)$ & $8 / 33.3$ & $/$ & \\
Kidney biopsy intimal hyalinosis $(\mathrm{n} / \%)$ & $7 / 29$ & $/$ \\
Moderate stage lupus retinopathy (n/\%) & $20 / 83.3$ & & \\
Severe stage lupus retinopathy $(\mathrm{n} / \%)$ & $3 / 12.5$ & $/$ & \\
\hline
\end{tabular}

BCVA: best-corrected visual acuity, SLEDAI-2K: Systemic Lupus Erythematosus Disease Activity Index 2000, BUN: blood urea nitrogen; GMN: glomerulonephritis 


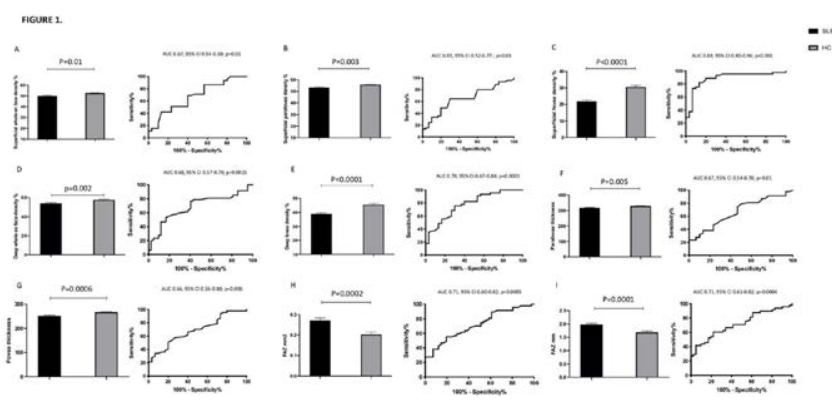

Disclosure of Interests: None declared

DOI: 10.1136/annrheumdis-2021-eular.2637

\section{POS1396 DAMAGE PROGRESSION OF FINGER JOINT CARTILAGE EVALUATED BY ULTRASOUND AND X-RAY IN PATIENTS WITH RHEUMATOID ARTHRITIS (RA)}

T. Ogura ${ }^{1}$, A. Hirata ${ }^{1}$, Y. Inoue ${ }^{1}$, T. Kagtagiri ${ }^{1}$, Y. Takakura ${ }^{1}$, H. Kameda ${ }^{1} .{ }^{1}$ Toho University, Division of Rheumatology, Department of Internal medicine, Tokyo, Japan

Background: Cartilage damage in RA has been evaluated by joint space narrowing (JSN) in X-ray, while it is not a direct evaluation of cartilage. Previously we have confirmed the usefulness of the direct imaging of finger joint cartilage by ultrasound (US) in patients with RA [1].

Objectives: We aimed to examine the temporal changes of US cartilage thickness in RA patients.

Methods: We enrolled 53 RA patients in whom the cartilage thickness of finger joints was measured by US and had radiographs of both hands at baseline and 1 -year later. The cartilage of metacapophalangeal and proximal interphalangeal joints of $2 n d$ to 5 th fingers were bilaterally visualized at the middle portion from a longitudinal dorsal view. Cartilage thickness was measured from the base of the cartilage to the interface artefact at the cartilage surface by static images. In addition, the JSN of the corresponding joints was scored using a hand X-ray by van der Heijde-modified Sharp method. Continuous variables from the two groups were analyzed using the Mann-Whitney $\mathrm{U}$ test or Wilcoxon signed-rank test. The relationships among the continuous variables were assessed using the Spearman's rank correlation coefficient.

Results: The median age of the patients was 68 years and the median disease duration was 6.3 years. The sum of total cartilage thickness from 16 joints per patient ranged from 3.1 to $9.1 \mathrm{~mm}$ (median $6.5 \mathrm{~mm}$ ) at baseline, and it was significantly correlated with total JSN score of the same joints $(\rho=-$ $0.63, p<0.001)$. The cartilage thickness was inversely correlated with disease duration (rho $=-0.40, p=0.003$ ), but not associated with age nor height. The decrease in cartilage thickness over 1 year was evident in patients with persistent moderate to high disease activity by the DAS28-CRP ( $n=10$; median
$-6.2 \%)$ as compared with other patients $(n=43$; median $-1.2 \%, p=0.004$ versus active patients)

Conclusion: This pilot study demonstrated the progression of cartilage damage by sustained RA activity, supporting the validity and usefulness of joint cartilage thickness evaluation by ultrasound in patients with RA.

REFERENCES:

[1] Ogura T, et al. Arthritis Care Res 2019 Oct 25.

Disclosure of Interests: None declared

DOI: 10.1136/annrheumdis-2021-eular.2784

\section{POS1397 HYDROXYCHLOROQUINE INDUCED RETINAL TOXICITY IN PATIENTS WITH RHEUMATIC DISEASES}

R. Maheshwari ${ }^{1}$, R. Sankaralingam2, S. Chinnadurai2, J. Antony2,

B. Chilukuri2, M. Mani2. ${ }^{1}$ Sri Ramachandra Institute of Higher Education and Research, Clinical Immunology and Rheumatology, Chennai, India;

${ }^{1}$ Sri Ramachandra Institute of Higher Education and Research, Clinical Immunology and Rheumatology, Chennai, India

Background: Retinal toxicity from hydroxychloroquine (HCQ) is rare, but the vision loss maybe irreversible and could have medicolegal consequences. Objectives: To determine the prevalence and assess the predictors of retinal toxicity due to $\mathrm{HCQ}$ in patients with rheumatic diseases. There is paucity of literature on retinal toxicity due to $\mathrm{HCQ}$ in rheumatic diseases.

Methods: A retrospective observational study was conducted in the Department of Clinical Immnuology and Rheumatology, Sri Ramachandra Institute of Higher Education and Research,Chennai, India from November 2018-May 2020, on patients taking $\mathrm{HCQ}$ for more than 6 months. All patients underwent ophthalmological screening at baseline and every 6 months, and thereafter by modern day screening methods-Humphrey Visual Field (HVF)10-2, Spectral Domain Optical Coherence Tomography(SD-OCT), except for patients with evidence of suspected retinal toxicity at baseline.Fundus autofluorescence (FAF) was done in feasible patients.

Results: 9 out of $743(1.2 \%)$ patients were identified to have retinal toxicity, detected via fundus examination ( $n=9)$, SD-OCT $(n=8 / 9)$, HVF 10-2 $(n=6 / 9)$, FAF $(n=1 / 9) .55 .5 \%(n=5 / 9)$ had Rheumatoid Arthritis(RA) and $44.4 \%(n=4 / 9)$ had Systemic Lupus Erythematosus(SLE) as their primary diagnosis. $77.7 \%(n=7 / 9)$ were females. The mean age was 47.5 years (20-72 years). $75 \%(n=3 / 4)$ of SLE patients were below 30 years of age. The average daily and cumulative dose of $\mathrm{HCQ}$ in these 9 patients were $244 \mathrm{mg}(200-400 \mathrm{mg})$ and $311.22 \mathrm{~g}(73-730 \mathrm{~g})$ respectively, whereas the mean recommended dose as per real body weight was $287.2 \mathrm{mg} /$ day. Average duration of HCQ consumption was 3.6 years (1-10 years). Only $11.1 \%(n=1 / 9)$ had presented with visual complaints of black floaters.

Conclusion: The asymptomatic nature of this irreversible toxicity, warrants frequent screening.Retinal toxicity was not age-related.Toxicity was manifested at low daily and cumulative doses.Screening should be done atleast every 6 months by fundus examination.Objective tests like HVF and SD-OCT should be done annually, especially in patients with underlying rheumatic diseases. The early manifestation of retinal toxicity in young SLE patients could have a genetic association and needs further evaluation.

Table 1. SALIENT FEATURES OF THE 9 PATIENTS PRESENTING WITH RETINAL TOXICITY DUE TO HCO

\begin{tabular}{|c|c|c|c|c|c|c|c|c|c|c|c|c|}
\hline \multirow[b]{2}{*}{$\begin{array}{l}\text { Sl. } \\
\text { No }\end{array}$} & \multirow[b]{2}{*}{ Age } & \multirow[b]{2}{*}{ Gender } & \multirow[b]{2}{*}{$\begin{array}{l}\text { Weight } \\
(\mathrm{Kg})\end{array}$} & \multirow[b]{2}{*}{$\begin{array}{l}\text { Primary } \\
\text { Diagnosis }\end{array}$} & \multicolumn{3}{|l|}{ Dose } & \multirow[b]{2}{*}{$\begin{array}{l}\text { Duration } \\
\text { (Years) }\end{array}$} & \multicolumn{4}{|l|}{ Detection Method Used } \\
\hline & & & & & $\begin{array}{l}\text { Recommended } \\
\text { Dose } \\
\text { (mg/Day) }\end{array}$ & $\begin{array}{l}\text { Received } \\
\text { Dose } \\
\text { (mg/Day) }\end{array}$ & $\begin{array}{l}\text { Cumulative } \\
\text { Dose } \\
\text { (grams) }\end{array}$ & & $\begin{array}{l}\text { FUNDUS } \\
\text { EXAM. }\end{array}$ & SD-OCT & $\begin{array}{l}\text { HVF } \\
10-2\end{array}$ & $\begin{array}{l}\mathrm{F} \\
\mathrm{AF}\end{array}$ \\
\hline 1 & 47 & $\mathrm{~F}$ & 58 & SLE & 290 & 400 & 438 & 3 & RPE Changes & Thinning/Photoreceptor Loss & Defects seen & - \\
\hline 2 & 20 & $\mathrm{~F}$ & 46 & SLE & 230 & 200 & 146 & 2 & $\begin{array}{l}\text { Multiple Small Drusens In } \\
\text { Paramacular Area }\end{array}$ & $\begin{array}{l}\text { Multiple } \\
\text { Drusens }\end{array}$ & Normal & $\begin{array}{l}\text { Perifoveal autofluo- } \\
\text { rescence spots- } \\
\text { drusens }\end{array}$ \\
\hline 3 & 23 & $\mathrm{~F}$ & 50 & SLE & 250 & 400 & 146 & 1 & RPE Changes & $\begin{array}{l}\text { RPE } \\
\text { Disruptions }\end{array}$ & Defects seen & - \\
\hline 4 & 30 & $\mathrm{~F}$ & 55 & SLE & 275 & 200 & 73 & 1 & Normal & Normal & Paracentral Scotoma & - \\
\hline 5 & 50 & $\mathrm{~F}$ & 49 & $\mathrm{RA}$ & 245 & 200 & 511 & 7 & $\begin{array}{l}\text { Early Bull's Eye } \\
\text { Maculopathy }\end{array}$ & $\begin{array}{l}\text { RPE } \\
\text { Atrophy }\end{array}$ & Defects seen & - \\
\hline 6 & 72 & $\mathrm{~F}$ & 60 & RA & 300 & 200 & 730 & 10 & $\begin{array}{l}\text { RPE Atrophy } \\
\text { FR Absent }\end{array}$ & $\begin{array}{l}\text { RPE } \\
\text { Atrophy }\end{array}$ & $\begin{array}{l}\text { General reduction in } \\
\text { sensitivity }\end{array}$ & - \\
\hline 7 & 65 & $M$ & 57.4 & RA & 287 & 200 & 146 & 2 & RPE Changes & $\begin{array}{l}\text { RPE } \\
\text { Disruptions \& Thinning Noted }\end{array}$ & Defects seen & - \\
\hline 8 & 62 & $\mathrm{~F}$ & 70 & RA & 350 & 200 & 219 & 3 & Chorioretinal Atrophy & $\begin{array}{l}\text { Altered } \\
\text { RPE } \\
\text { Membrane }\end{array}$ & Defects seen & - \\
\hline 9 & 59 & M & 71.6 & RA & 358 & 200 & 292 & 4 & RPE Changes & $\begin{array}{l}\text { RPE } \\
\text { Disruptions }\end{array}$ & Normal & - \\
\hline
\end{tabular}

F:Female; M:Male; SLE:Systemic Lupus Erythematosus; RA: Rheumatoid Arthritis, FUNDUS EXAM.: Fundus Examination; SD-OCT:Spectral Domain-Optical Coherence Tomography, HVF 10-2:Humphrey Visual Field 10-2; FAF: Fundus Autofluorescence, RPE:Retinal Pigment Epithelium; FR:Foveal Reflex 